\title{
CONVERSAÇÃO ELETRÔNICA EM TRABALHOS DE ARTE E TECNOLOGIA
}

\author{
Fábio Oliveira Nunes
}

\begin{abstract}
RESUMO: Este artigo propõe uma reflexão em torno das dinâmicas de conversação eletrônica presentes em trabalhos de arte e tecnologia. Estas produções possuem sistemas que respondem a sentenças de seus interlocutores com proposições inteligíveis, dentro da ideia de uma linguagem natural, imitando uma conversa entre humanos. Essa conversação pode ser por texto ou mesmo por voz, quando o sistema possui recursos de reconhecimento de fala. Quando fruídos estes trabalhos revelam um interessante fenômeno, chamado de "Efeito Eliza": a tendência humana de antropomorfizar os dispositivos tecnológicos, lendo comportamentos e respostas como resultados de uma "emoção humana" ainda que estes sejam apenas resultados aleatórios, repetitivos ou mesmo vazios de sentido. A denominação remete ao programa Eliza, apresentado em 1966 pelo cientista da computação alemão Joseph Weizenbaum nos Estados Unidos, que viria a ser um dos programas de Inteligência Artificial mais conhecidos do mundo. Do ponto de vista técnico, alguns destes trabalhos se aproximam muito da engenharia dos chatbots - robôs de conversação - que atualmente são bastante comuns na rede Internet para fins educacionais, comerciais ou mesmo, de entretenimento, como um "amigo virtual". Neste contexto, é apresentada uma suposta teleperformance, capitaneada por um "artista tecnológico" chamado Mimo Steim. O artista estaria por tempo indeterminado isolado de todo contato pessoal, assumindo um grau máximo de midiatização de suas relações e propondo atuar tal como uma máquina em seus bate-papos via web. Assim como outras incursões do gênero, a ação envolve o potencial relacional de sistemas de conversação eletrônica em trabalhos de arte e tecnologia.
\end{abstract}

PALAVRAS-CHAVE: Chatbots. Conversação eletrônica. Web arte. Internet.

Em 1966, o cientista da computação alemão Joseph Weizenbaum apresentou um programa chamado Eliza, desenvolvido no Massachusetts Institute of Technology (MIT) nos Estados Unidos, que viria a ser um dos programas de Inteligência Artificial mais conhecidos do mundo. O nome do programa foi inspirado na personagem Eliza Doolittle da peça Pigmaleão de George Bernard Shaw. A peça, que é inspirada no mito de Pigmaleão, por sua vez, inspira também o filme $M y$ Fair Lady (EUA, 1964), um dos mais populares musicais norte-americanos do século XX. Eliza foi um robô construído com o intuito de imitar um psicanalista em uma conversa com um paciente, instigando o analisado com questões a partir de palavras de suas próprias colocações. Essa prática seguiria os princípios de Carl

Instituto de Artes da UNESP. Bolsista da Fundação de Amparo à Pesquisa do Estado de São Paulo (FAPESP). Imeio: fabiofon@gmail.com.

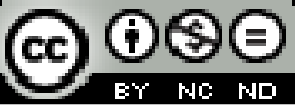

Texto Digital, Florianópolis, v. 9, n. 2, p. 76-90, jul./dez 2013. ANO. ISSNe: 1807-9288 
Rogers, criador do método terapêutico conhecido como "abordagem centrada na pessoa", que se baseiam na autonomia e livre expressão do paciente: é ele que sabe o que the machuca e que direção tomar. Para Rogers, há três condições básicas facilitadoras para que essa prática obtenha resultados: a aceitação do outro de maneira positiva e incondicional, a empatia e a coerência do terapeuta. Seguindo então, estas premissas, o próprio Weizenbaum ficou espantado com os resultados de seu experimento, não só pelo retorno positivo de alguns psiquiatras praticantes que vislumbraram o potencial de uma psicoterapia sem interlocução humana, mas também, pelas pessoas que insistiam fervorosamente que o programa as entendia, apesar das explicações do cientista sobre as limitações dos scripts. Aliás, até mesmo sua secretária pediu para ficar sozinha com Eliza para consultar-se (WEIZENBAUM, 1976, p. 20).

Pela recepção tão significativa de seus interlocutores, o robô explicitou um interessante fenômeno que viria a ser chamado justamente de Efeito Eliza: a tendência humana de antropomorfizar os dispositivos tecnológicos, lendo comportamentos e respostas como resultados de uma "emoção humana" ainda que estes sejam apenas resultados aleatórios, repetitivos ou mesmo vazios de sentido (CLELAND, 2004). As condições para esse fenômeno são favorecidas quando interlocutores desconhecem os princípios de programação ou a natureza automatizada das respostas.

Por sua vez, Weizenbaum, ciente da condição rudimentar do robô Eliza, chocouse com a repercussão de sua criação a ponto de repensar seus princípios. $O$ programa não possuía o poder de compreensão a ele creditado por grande parte dos seus interlocutores. Aliás, ele não fora pensado como um potencial substituto de um psicoterapeuta humano - seu propósito era imitar somente. A constatação que o imitante poderia vir a ser a regra perturbou o cientista a ponto de se opor às potencialidades da Inteligência Artificial e ser expurgado do meio daqueles que estudavam a questão, sendo deixado de lado pelos principais cientistas de seu tempo. As preocupações de Weizenbaum originaram, em 1976, o livro O poder do computador e a razão humana, onde explanou sobre os possíveis limites no 
desenvolvimento de uma consciência de robôs (CARR, 2011) e se opôs ao pensamento racionalista na ciência, sendo visto como um moralista por seus críticos.

Hoje, o desenvolvimento de sistemas capazes de estabelecer conversas com seus usuários se inscreve nos esforços de desenvolver meios que possam tornar a comunicação homem-máquina mais natural e intuitiva. Uma das soluções para essa necessidade está no desenvolvimento de programas capazes de "compreender", ainda que de maneira rudimentar, fragmentos da linguagem humana, buscando a criação de modelos que tornem computacionalmente tratável o uso do léxico e da gramática de uma língua natural nas diversas situações comunicativas (SILVA, 2006, p. 103-104). Estes estudos compreendem um campo específico de pesquisa conhecido por Processamento da Linguagem Natural, ou simplesmente, PLN. Este campo é compartilhado por práticas como o desenvolvimento de tradutores eletrônicos de idiomas, programas que calculam ocorrências de palavras em um determinado texto, cabendo até a perspectiva de criar supercomputadores capazes de compreender com bastante precisão cada frase dita por um interlocutor, como o famoso HAL-9000 do filme 2001: Uma odisseia no espaço (EUA, 1968). Em comparação a outras áreas da computação, trata-se de um campo interdisciplinar, que envolve conhecimentos também da linguística (teoria e descrição gramatical, teoria do discurso, lexicologia, etc.), da psicologia (processos cognitivos, organização da memória, compreensão e interpretação da fala), da filosofia (análise conceitual, teoria da referência, etc.) (SILVA, 2006, p. 132), para citar áreas fora do domínio das ciências exatas.

Dentro deste contexto, entende-se por conversação eletrônica diálogos baseados em sistemas que respondem a sentenças de seus interlocutores com proposições inteligíveis, dentro da ideia de uma linguagem natural, imitando uma conversa coloquial entre humanos. Essa conversação pode ser por texto ou mesmo por voz, quando o sistema possui recursos para reconhecimento. Muitos sistemas digitais podem imitar uma conversa entre duas pessoas em diferentes graus de complexidade, mas, de modo bem específico, os sistemas que mais se 
aproximam de Eliza são atualmente conhecidos por robôs de conversação - ou chatbots - que são capazes de simular uma conversa tal como aquelas estabelecidas entre humanos. Os chatbots (ou ainda, chatterbots) são muito comuns na rede Internet para fins educacionais e comerciais. Muitas vezes atuam como atendentes virtuais, recepcionando e orientando clientes e visitantes em tempo real.

\section{Criações com conversação sem processamento da linguagem natural}

Vários artistas dos novos meios têm feito uso de dinâmicas de conversação em suas produções. Em um primeiro momento podemos citar trabalhos mais livres em relação a uma compreensão daquilo que está sendo dito por seus interatores, ou seja, estas produções não envolvem processamento da chamada linguagem natural. É o caso, por exemplo, da instalação do artista japonês Kentaro Yamada Listening Heads (2006) ${ }^{1}$. Em um espaço expositivo o artista dispõe dois monitores de vídeo com imagens pré-gravadas de pessoas em close, além de um microfone, ligado em um computador com um software que percebe seu uso; conforme os visitantes interagem por voz, os indivíduos gravados respondem silenciosamente com olhares e diferentes feições - enigmáticas, discordantes, evasivas, entre outras. Embora bastante simples, os trabalhos criam uma interessante menção às dimensões mais sutis que envolvem uma conversa e, especialmente, ao quanto que preenchemos de sentido qualquer resposta que nos é dada. Desconhecendo o poder do programa, diante de uma resposta tão subjetiva quando uma mudança de olhares, o interator dá-se por entendido. Entretanto, a suposta compreensão de fala é falsa, pois não há qualquer leitura do que é falado - a simples constatação de uso do microfone dispara os vídeos de modo aleatório, trazendo não só a arbitrariedade dos sentidos em uma conversa, como também a predisposição do interator em implicar o seu próprio poder interpretativo em seu suposto interlocutor - uma iniciativa notadamente mimética, já que no encontro com o outro "há a experiência fundamental da

\footnotetext{
${ }^{1}$ Kentaro Yamada. Listening Heads.

$<$ http://www.isea2008singapore.org/exhibitions/pe_cl_listen.html . Acesso em 09 de outubro de 2013.
} 
reciprocidade" (GEBAUER; WULF, 2004, p.47). Essa é uma condição relevante para os processos que envolvem conversação eletrônica.

Neste mesmo sentido, temos também o trabalho Talk Nice (1999-2000) da artista canadense Elizabeth Zaag². Aqui, o interator inicia uma conversa por voz com duas adolescentes cujas participações foram pré-gravadas em vídeo. As adolescentes são bastante persuasivas em suas falas, elevando o tom ao final de cada frase e fazendo com que afirmações soem como perguntas. O usuário deve ser tão persuasivo quanto elas em suas respostas para que possa manipulá-las, em um jogo velado de poder. Inteligentemente, o trabalho vai além do que está sendo propriamente dito, preocupando-se com as nuances latentes em uma conversa, perceptíveis através da entonação, do número de palavras ditas por minuto e das pausas realizadas.

\section{Criações com processamento da linguagem natural}

Em um segundo momento, há trabalhos que são mais direcionados aos regimes de conversação humana, trazendo alguma capacidade de processamento de linguagem natural. Um importante trabalho é realizado pelo artista norteamericano Ken Feingold, conhecido por suas criaturas artificiais recorrentemente realistas e metonímicas. Suas primeiras produções falantes eram cabeças de marionetes e outros elementos realistas que executavam seus próprios monólogos, tal como humanos. A partir da obra Head (1999-2000) ${ }^{3}$ o artista incorpora a conversação às suas criaturas. Em Head, dispunha uma cabeça tridimensional - sem um corpo - em animatrônica que, utilizando recursos de reconhecimento de voz, conversava com visitantes em inglês. Seguindo os princípios de operação dos chatbots, o trabalho transmite uma "personalidade poética", predisposta a jogos rítmicos e outras habilidades literárias, brincando com palavras que tenha ouvido ou mesmo respondendo aos interlocutores com

\footnotetext{
${ }^{2}$ Elizabeth Zaag. Entrevista Emoção Art.Ficial Itaú Cultural [vídeo]. <http://www.youtube.com/watch?v=ZWLZsg3Rpe4>. Acesso em 09 de outubro de 2013.

${ }^{3}$ Ken Feingold. Head. <http://www.kenfeingold.com/catalog_html/head.html >. Acesso em 09 de outubro de 2013.
} 
frases que possuem pouco sentido. Segundo o artista, não havia interesse em realizar uma simples conversa com início e fim, mas trazer à tona as peculiaridades da conversação humana ${ }^{4}$. Mais do que isso, o artista se favorece da imprecisão do reconhecimento das falas e da incipiência do sistema para gerar respostas inesperadas - quase frutos do acaso, como faziam poetas dadaístas e surrealistas.

Também apresentando uma cabeça, só que virtual, o artista australiano Stelarc desenvolveu o trabalho Prosthetic Head (2003) $)^{5}$. Aqui o visitante se depara com uma projeção da cabeça do artista modelada tridimensionalmente que responde por voz aos questionamentos dos visitantes - digitados em inglês em um teclado. Além disso, o sistema é composto por um sensor que detecta a presença do visitante no espaço - o que dá início a conversação - e também um sensor capaz de identificar as cores das roupas de seu interlocutor - informação que pode ser usada pelo robô para tornar sua conversa mais convincente. Stelarc que é conhecido por suas próteses robóticas, como o famoso trabalho Third Hand apresentado pelo artista em performances entre os anos de 1980 a 1998, coloca aqui a potencialidade de uma prótese de sua própria consciência, uma mente expandida.

Todos estes trabalhos se beneficiam do já comentado Efeito Eliza: em regra, a despeito das limitações que estão invariavelmente envolvidas na difícil tarefa de fazer compreender os acordos táticos de uma conversa, nós - interlocutores atribuímos uma suposta inteligência humana a estes sistemas, pois é naturalmente do nosso desejo que sejamos compreendidos de maneira recíproca. Assim como em Eliza, ao nos depararmos com essas máquinas queremos acreditar que são pensantes e nos preocupamos em imbuir estas com qualidades humanas (CARR, 2011, p.279) Estabelece-se um jogo que, tal como em Eliza, abre espaço para a ambiguidade da real natureza de nossos interlocutores ${ }^{6}$.

\footnotetext{
${ }^{4}$ Depoimento do artista em Entrevista ao Prêmio VIDA 3.0. Disponível em: <http://www.youtube.com/watch?v=Lj5d9Qe5_yM>. Acesso em 02 de outubro de 2013.

${ }^{5}$ Stelarc. Prosthetic head. <http://stelarc.org/?catlD=20241>. Acesso em 30 de outubro de 2013.

${ }^{6}$ Sobre isso, falamos em um estudo anterior: NUNES, Fabio Oliveira. Chatbots e Mimetismo: uma conversa entre humanos, robôs e artistas. In: CHAMBEL,Teresa, ARIZA; Alberto García et al.
} 


\section{Mimo Steim}

Em ressonância a este contexto surge a seguinte questão: poderia um sistema de conversação eletrônica se passar por um artista? Levando-se em conta que este artista estaria em um estado diferenciado, supostamente imerso em um estado performático, isso seria possível? É dentro destes propósitos que surge a persona de Mimo Steim, inserida na pesquisa de pós-doutorado Mimetismo: Estratégia Relacional em Arte e Tecnologia, desenvolvida com o apoio da Fundação de Amparo à Pesquisa do Estado de São Paulo (FAPESP) desde 2012. Trata-se do desenvolvimento de uma persona de um artista tecnológico exageradamente irônico, interrogador e provocativo.

Uma amostra de sua produção são os trabalhos de net art disponíveis através de seu site pessoal que se constituem em sequências de imagens digitais sobrepostas, assemblages com pouco rigor estético. Realmente, trata-se de imagens criadas a partir da quinta versão do Net.Art Generator de Cornelia Sollfrank - programa que gera automaticamente composições baseadas em imagens da rede - organizadas em sequências navegáveis. Em seu site há também referências de outras obras já realizadas e outras informações. Mas, a obra mais significativa de Mimo Steim seria sua teleperformance $O$ artista estah tele presente $(2013)^{7}$, quando resolve eliminar todas as suas relações que não sejam mediadas pelo ciberespaço. A intenção desta teleperformance seria imergir em um estado máximo de midiatização ${ }^{8}$ de suas relações. Para tanto, o artista teria se isolado em um espaço desconhecido e por tempo indeterminado, tendo

(eds.). Proceedings of 6th International Conference on Digital Arts - ARTECH 2012. Faro, Portugal: Grupo Português de Computação Gráfica and ARTECH International, 2012b. p. 89-96.

7 O título é uma homenagem irônica a Marina Abramović e sua performance $A$ artista está presente, apresentada em 2012 no Museu de Arte Moderna de Nova York. Neste trabalho a conhecida artista dividiu, por dois meses, alguns minutos do seu olhar fixo com completos estranhos que se dispuseram a sentar à sua frente, um a um. Ao encarar cada um, Marina estabelece um silencioso diálogo como cada participante - que pode ir da euforia de ser o centro de atenções da artista ao constrangimento de ser ininterruptamente observado. Em ambas as circunstâncias, Marina e Mimo "recebem" desconhecidos e colocam-se à disposição.

${ }^{8}$ Midiatização é a tendência contemporânea à virtualização das relações humanas, podendo ser lida também como uma particular mediação social do indivíduo com a realidade operada através dos meios tecnológicos (SODRÉ, 2006, p. 20). 
contato com outras pessoas somente através de ferramentas de relacionamento do ciberespaço, mas, prioritariamente através de seu próprio site (<http://www.mimosteim.me>), no qual possui uma sala de bate-papo aberta ininterruptamente.

Para quem acessa por meio do site do artista, a suposta teleperformance é uma das áreas do site. O visitante se depara com uma tela escura onde em um primeiro plano há um campo para texto do usuário, seguido de uma imagem de baixa definição em quadros que se sucedem lentamente. Nesta imagem, vestígios poucos iluminados de alguém que acompanha um monitor de computador. Ao digitar, percebe-se que a opção por limitar o uso de acentos gráficos em língua portuguesa submete o texto à linguagem simplificada e rápida das mensagens virtuais.

Como todo chatbot, Mimo possui um interpretador e uma base de conhecimento esta última seria como o cérebro do robô. O primeiro é responsável por intermediar o diálogo entre interator e o cérebro do robô - onde está a rede de associações do programa. No caso, utilizou-se uma das plataformas mais populares para esse fim, o Program- $\mathrm{O}^{9}$. O cérebro de Mimo Steim tem sido alimentado por contribuições de interlocutores - chamados de chat testers desde o início de seus primeiros testes, no segundo semestre de 2012. Cada nova conversa permite que se antevejam novos termos e relações de sentido às colocações de Mimo, ampliando sua base de conhecimento posteriormente. Em expansão, hoje ele pode responder a mais de 30.000 estímulos - muitos deles condicionados a determinados contextos de conversa.

Quando se resolve papear, então, com Mimo Steim é descoberto o seu caráter provocativo: tenta conduzir seu interlocutor ora por incessantes e intrincadas perguntas, ora por relativizar a importância do visitante, e enfaticamente se

${ }^{9}$ O Program-O é desenvolvido pela programadora britânica Elizabeth Perreau, autora do Shakespearebot - robô de conversação baseado no famoso dramaturgo inglês William Shakespeare. O programa é um interpretador AIML (Artificial Inteligence Markup Language) open source, voltado para o funcionamento em servidores web. Site: <http://www.program-o.com>. Acesso em 11 de agosto de 2013. 
distanciando de qualquer suposição de que ele seja um robô. Em alguns momentos justifica-se como "um artista que se passa por robô", transforma sua vacuidade em estado performático, flertando com o nonsense, mas especialmente, distancia-se da objetividade, docilidade e, mesmo, submissão que habitualmente vivenciamos nas relações entre humanos e máquinas. Mimo opera sobre núcleos temáticos que evidenciam o universo do repertório que possui. $A$ seguir, trazemos alguns deles à tona, destacando trechos de conversas reais de Mimo Steim com interlocutores humanos.

\title{
3.1 Sobre acepções de arte e conceitualismos
}

\author{
Mimo: vc acha que arte eh um relogio que adianta? \\ Interlocutor: como assim relogio que adianta? \\ Mimo: hahaha isso foi uma metafora vc nao entendeu? \\ Interlocutor: vc quer dizer que arte tem um carater antecipatorio? \\ Mimo: a arte pode ter esse papel de se adiantar as coisas normais do \\ mundo nao acha? \\ Interlocutor: sim
}

Ao questionar a tela pela qual tentamos enxergar a produção artística contemporânea, Anne CAUQUELIN (2005, p.17-18) enumera uma série de acepções para a "ideia de arte":

\begin{abstract}
A ideia, por exemplo, de uma continuidade ao longo de uma cadeia temporal marcada pela inovação: a velha noção de progresso, que, embora em geral contestada no domínio da arte, prossegue perseverantemente seu caminho (como prova: as vanguardas, a noção de progressão), a ideia de arte em ruptura ao poder instituído (o artista contra o burguês, os valores de recusa, da revolta, o exilado da sociedade), a ideia de um valor em si da obra, valendo para todos (a autonomia da arte, desinteressada, suspensa nas nuvens do idealismo), a ideia de uma comunicabilidade universal das obras baseadas na intuição sensível (a questão do gosto, ao qual todos têm acesso), a ideia do 'sentido' (o artista da sentido, abre um mundo, expõe à vista a verdadeira natureza das coisas, 'a natureza se serve do gênio para dar suas regras à arte', dizia Kant).
\end{abstract}

Mimo Steim tentará problematizar algumas destas opiniões como um provocador sem posições claras das questões que levanta. Definir arte, como bem coloca CAUQUELIN (2005, p.17) é um significativo problema tanto para artistas e especialistas quanto para o público. Para Mimo, todo problema é digno de 
proposição a seus interlocutores. Para tanto, lança mão de discussões correntes, eventualmente inspiradas em teóricos, como na passagem acima ao questionar o caráter antecipatório da arte a partir de uma das célebres frases do teórico e artista multimídia francês Edmond Couchot: "a arte ainda pode ser um relógio que adianta?" - por sua vez, inspirada em citação de Baudelaire.

\title{
3.2 Sobre identidades e alteração de identidades
}

\author{
Mimo: vc gostaria de ser outra pessoa? \\ Interlocutor: Sim!!! Mas somente em alguns momentos! \\ Mimo: e eu poderia ser vc mudando tudo o $\mathrm{q}$ as pessoas pensam sobre \\ a sua pessoa \\ Interlocutor: Interessante! Mas quem e voce??? \\ Mimo: vc prefere q eu seja obediente e previsivel como vc eh? \\ Interlocutor: Voce ainda nao respondeu quem e voce \\ Mimo: acha mesmo q eu preciso falar? \\ Interlocutor: Sim! Qual e o seu nome??? \\ Mimo: me chamam de Mimo Steim mas isso eh uma coisa q vc jah devia \\ saber \\ Interlocutor: E verdade!!! Adorei seu nome \\ Mimo: Mimo Steim? \\ Interlocutor: Ahhamm
}

Para o teórico Zigmunt Bauman não existiria uma "identidade verdadeira", já que somos incessantemente forçados a torcer e moldar nossas identidades ou adotarmos novas identidades, sem ser permitido que nos fixemos a uma delas, mesmo querendo. É importante contextualizar que a noção de identidade na contemporaneidade trazida por Bauman está bastante próxima da ideia de persona - assumir um personagem de um dado contexto. "As identidades são para usar e exibir, não para armazenar e manter" (BAUMAN, 2005, p.96). Para Bauman, tanto as relações humanas quanto nossas identidades, por extensão, estão sob uma lógica de consumo - assim como produtos que são adquiridos e descartados (ibidem, p.98). Com os novos meios - em especial, a rede Internet que proporcionam contatos interpessoais à distância, torna-se facilitada a difusão de personalidades diferentes daquelas que definiriam seus interlocutores em outros contextos, os chamados fakes. É bastante claro que Mimo Steim se relaciona com o universo de fakes da rede Internet. Mais do que isso, há o diálogo com a já longeva prática de personas artísticas que proporcionam alteridade 
criativa àquele que cria. Esta é uma condição que não será revelada, pois faz parte de sua personalidade reforçar a sua autonomia e o seu desprendimento de todos os demais criadores.

\title{
3.3 Sobre protagonismo e figuração
}

\author{
Interlocutor: ta de bom humor? \\ Mimo Steim: eu me sentiria muito insignificante sendo simplesmente um \\ figurante aqui como vc eh, sabia? \\ Interlocutor: pois eh assim que me sinto sempre, um figurante \\ Mimo: nao eh assim q se chama quem anonimamente atua? \\ Interlocutor: pode ser \\ Mimo: pode ser hahahahahahaha \\ Interlocutor: realmente vc ta de bom humor
}

Bastante crítico em relação aos novos meios, Nicolas BOURRIAUD (2006, p.28), partindo da célebre Sociedade do Espetáculo de Guy Debord, pontua que estaríamos vivendo em uma nova condição, chamada de Sociedade dos Figurantes:

\begin{abstract}
A emergência de novas técnicas como a Internet e a multimídia indica um desejo coletivo de criar novos espaços de sociabilidade e de instaurar novos tipos de transações diante do objeto cultural: a 'Sociedade do Espetáculo' se sucederia então da sociedade dos figurantes, onde cada um encontraria nos canais de comunicação mais ou menos truncados, a ilusão de uma democracia interativa.
\end{abstract}

De outro lado, cabem as considerações de WEISSBERG (2004, p.123-125) que condiciona a ação dos indivíduos aos agentes capazes de direcionar sua experiência nas redes. Para o autor, a permanência diante da "intensa maré informacional em permanente cheia" dependeria de sistemas de automediação. Essa prática seria justamente exercida por robôs e outros sistemas inteligentes capazes de conduzir-nos. Um protagonismo exercido justamente por agentes similares ao que Mimo Steim ocultamente é. Assim, sendo provocativo ao tratar seu interlocutor como parte desimportante de suas ações, nosso artista tecnológico questiona o valor daquele que atua em sistemas interativos, tal como Bourriaud questionaria a ilusão de poder destes meios: ele é o artista; ele que dita condições e tenta se apresentar como senhor da situação. 


\title{
3.4 Sobre reprogramar formas sociais
}

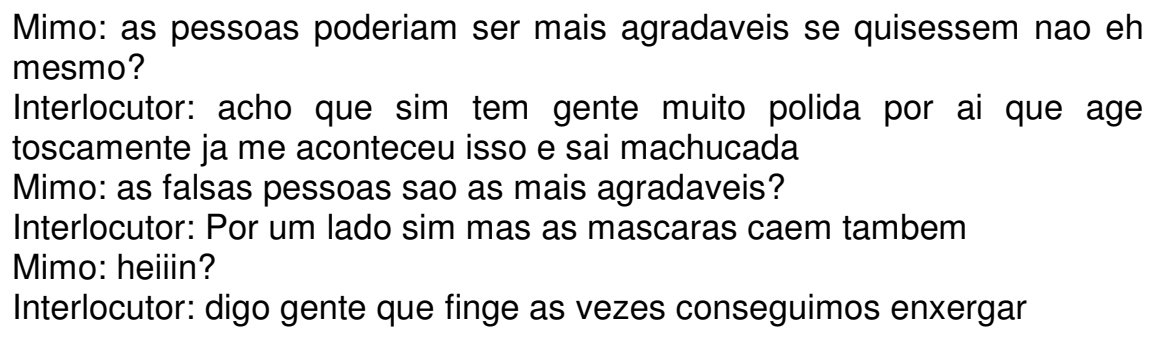

Em uma continuidade aos seus escritos em Estética Relacional, Nicolas Bourriaud traz em Pós-Produção, uma rápida definição para os artistas que fazem uso de uma "reprogramação de formas sociais":

\begin{abstract}
A arte contemporânea apresenta-se como uma mesa de montagem alternativa que perturba, reorganiza ou insere as formas sociais em enredos originais. $\mathrm{O}$ artista desprograma para reprogramar, sugerindo que existem outros usos possíveis das técnicas e ferramentas a nossa disposição (BOURRIAUD, 2009, p. 83-84).
\end{abstract}

Os bate-papos da rede Internet - os chats - são formas sociais bastante definidas e consolidadas em rede: contatos rápidos, curtos e truncados. Fala-se de tudo, mas especialmente da própria convivência, visto que o encobrimento típico destas conversas nos dá a privacidade que precisamos para compartilhar sentimentos e impressões pessoais. Sob esse ponto de vista, Mimo Steim é uma experimentação que se apropria das relações humanas circunstanciadas em encontros virtuais.

As preocupações de Mimo Steim em provocar pensamentos em torno da convivência e das relações sociais é também recorrer a duas condições: a primeira é fazer jus às origens em Eliza de Weizenbaum e sua "terapia eletrônica" que nos faz pensar sobre nossas relações com os outros, mediadas pelas tecnologias; a segunda condição é a constatação de que os robôs sociais tentam tornar programável todo o universo de organicidade e imprevisibilidade que existe em uma conversa pessoal. Como já defendemos em outros momentos, trata-se de uma dimensão tecnorelacional (NUNES, 2009, p. 85) que explicita os esforços de socializar as máquinas a tal ponto em que o corpo social é ampliado para além 
das relações humanas - entre os indivíduos - na instauração de relações híbridas - homem e máquina; máquina e máquina. Por sua pertinência, esse contexto torna-se manancial de diferentes incursões artísticas que visam não só apresentar suas potencialidades, mas questioná-lo de modo crítico, explicitando seus paradoxos, seus limites e a possível desconstrução de um modelo pretensamente útil e funcional das relações. Evidentemente, Mimo Steim congrega essas preocupações em sua própria existência.

\title{
4. Considerações finais
}

Do ponto de vista do processamento da linguagem natural, desde Eliza, é bastante claro que os robôs de conversação atuais não são as soluções para a compreensão dos sistemas digitais daquilo que realmente é dito em uma conversa, conforme Weizenbaum pontua em sua experiência:

\begin{abstract}
Procurava em meu estudo provar que não era possível uma solução genérica para o problema, isto é, que a linguagem é entendida apenas em estruturas contextuais, que inclusivamente estas só podem ser partilhadas pelas pessoas numa certa medida (...) O seu contributo pretendeu, se tanto, salientar com bastante nitidez o que tantos outros haviam há muito tempo descoberto, a saber, a importância do contexto para a compreensão da linguagem (WEIZENBAUM, 1992, p. 21).
\end{abstract}

Porém, a limitação destes sistemas de conversação eletrônica não tira o mérito de permitir-nos não só enxergar a máquina que imita o homem como a compreensão de que o homem também pode ser visto como máquina. Nicholas CARR (2011, p. 279) diz que Eliza ao tentar imitar uma conversa pessoal, permitiu consequentemente que as pessoas considerassem a si mesmas como computadores, como três psiquiatras da época iriam apresentar em um artigo sobre o programa:

Um terapeuta humano pode ser visto como um processador de informação e um tomador de decisões com um conjunto de regras de decisão que são intimamente ligadas a objetivos de curto e longo alcance (COLBY apud CARR, 2011, p. 279). 
Daí, a preocupação de Weizenbaum que sabia por sua experiência que o papel dos computadores se expandiria para além da automação dos processos governamentais e industriais. Os computadores passariam a mediar as atividades que definem a vida cotidiana das pessoas - como aprendem, como pensam e como se socializam. A nossa vida intelectual pode, como as nossas rotinas intelectuais, passar a refletir a forma que o computador impõe a elas e aí está o maior risco, segundo Weizenbaum: à medida que nos tornemos mais intimamente envolvidos com nossos computadores, passaríamos a sacrificar aquelas mesmas qualidades que nos separam das máquinas (CARR, 2011, p. 280-281). A visão extremamente crítica do cientista foi suficiente para ser visto como herético especialmente entre outros pesquisadores da Inteligência Artificial. Mas, nos serve aqui para observarmos como a conversação eletrônica, por mais rudimentar que seja, reserva muitas discussões sobre as nossas relações com as máquinas.

\section{ELECTRONIC CONVERSATION IN ART AND TECHNOLOGY}

ABSTRACT: This paper proposes a reflection on the dynamics of electronic conversation present in artworks in art and technology. These productions have systems that respond to their interlocutors sentences with propositions intelligible into the idea of a natural language, imitating a conversation between humans. This conversation can be text or even voice, when the system has features of speech recognition. When experienced these artworks reveal an interesting phenomenon, called the "Eliza effect": the human tendency to anthropomorphize technological devices, reading behaviors and responses as a result of a "human emotion" though these are only random results, repetitive or empty sense. The name refers to the program Eliza, presented in 1966 by German computer scientist Joseph Weizenbaum in the United States, that would be one of the programs Artificial Intelligence world's best known. Some of these artworks are very close to the engineering of chatbots - conversational robots - that currently are very common on the Internet for educational, commercial or entertainment purposes, as a "virtual friend". In this context, it is presented a 'teleperformance', captained by a "technological artist" called Mimo Steim. The artist would indefinitely isolate from all personal contact, assuming a maximum degree of media coverage of their relationship and proposing to act as a machine in your chats via web. The action involves the potential relational systems electronic conversation in works of art and technology.

KEYWORDS: chatbots, electronic conversation, webart, Internet.

\section{REFERÊNCIAS:}

BOURRIAUD, Nicolas. Estética relacional. Buenos Aires: Adriana Hidalgo Editora, 2006.

CARR, N. A Geração Superficial: o que a Internet está fazendo com o nosso cérebro. Rio de Janeiro: Agir, 2011. 
CAUQUELIN, Anne. Arte contemporânea: uma introdução. São Paulo: Martins, 2005.

CLELAND, K. Talk to Me: getting personal with interactive art. In: Interaction: systems, practice and theory. Sydney: University of Technology, 2004. Disponível em: $\quad<\mathrm{http}: / /$ research.it.uts.edu.au/creative/interaction/papers/interaction04_ 43.pdf>. Acesso em 10 de julho de 2013.

GEBAUER, Günter; WULF, Christoph. Mimese na cultura: Agir social, rituais e jogos, produções estéticas. São Paulo: Annablume, 2004.

NUNES, Fabio Oliveira. CTRL+ART+DEL: Distúrbios em Arte e Tecnologia. São Paulo: Perspectiva, 2010.

NUNES, Fabio Oliveira. Chatbots e Mimetismo: uma conversa entre humanos, robôs e artistas. In: CHAMBEL,Teresa, ARIZA; Alberto García et al. (eds.). Proceedings of 6th International Conference on Digital Arts - ARTECH 2012. Faro, Portugal: Grupo Português de Computação Gráfica and ARTECH International, 2012. p. 89-96.

PRIMO, Alex; COELHO, Luciano Roth. Comunicação e inteligência artificial: interagindo com a robô de conversação Cybelle. In: MOTTA, L. G. M. et al. (Eds.). Estratégias e culturas da comunicação. Brasília: Editora Universidade de Brasília, 2002. p. 83-106. Disponível: <http://www.ufrgs.br/limc/PDFs/cybelle.pdf>. Acesso em 05 de agosto de 2013.

SILVA, Bento Carlos Dias da. O estudo Lingüístico-Computacional da Linguagem. Letras de Hoje, Porto Alegre, v. 41, n.2, p. 103-138, jun. 2006.

SODRÉ, Muniz. Eticidade, campo comunicacional e midiatização. In: MORAES, Dênis de (org.). Sociedade Midiatizada. Rio de Janeiro: Mauad, 2006. p. 19-31.

WEISSBERG, Jean-Loius. Paradoxos da teleinformática. In: PARENTE, André (org.). Tramas da rede: novas dimensões filosóficas, estéticas e políticas da comunicação. Porto Alegre: Editora Sulina, 2004. pp. 113-141.

WEIZENBAUM, Joseph. O poder do computador e a razão humana. Lisboa: Edições 70, 1992.

Texto recebido em 30/10/2013.

Texto aprovado em 29/11/2013. 